\title{
Microsatellite instability in early onset and familial colorectal cancer
}

Cecilia Brassett, Johanna A Joyce, Nicola J Froggatt, Gareth Williams, Dominic Furniss, Sheila Walsh, Richard Miller, D Gareth R Evans, Eamonn R Maher

\section{Abstract}

Hereditary non-polyposis colorectal cancer syndrome (HNPCC) is often considered to be the most common form of inherited colorectal cancer, although its precise incidence is unknown. The clinical diagnosis of HNPCC relies on a combination of family history and young age of onset of colorectal cancer, but as many familial aggregations of colorectal cancer do not fulfil the strict diagnostic criteria, HNPCC might be underdiagnosed. The majority of HNPCC families have germline mutations in mismatch repair (MMR) genes, such as MSH2 or MLH1, so that HNPCC cancers characteristically exhibit DNA replication errors (RERs) at microsatellite loci. Although an RER positive phenotype in tumours can also result from somatic mutations in an MMR gene, the prevalence of RER + tumours should provide a maximum estimate of the incidence of germline MMR gene mutations in patients with early onset and familial colorectal cancer. We investigated colorectal cancers for RERs from (1) a population based study of 33 patients with colorectal cancer aged 45 years or less, (2) 65 kindreds with familial colorectal cancer which only partially fulfilled the criteria for the diagnosis of HNPCC, and (3) 18 cancers from 12 HNPCC kindreds. Seven of 33 patients (21\%) with colorectal cancer aged 45 years or less had an RER + cancer, with only two of these having a clear family history of HIPCC. A greater proportion of RER + tumours (5/7) occurred proximal to the splenic flexure than RER - tumours (4/26; $\left.\chi^{2}=6.14, p<0.025\right)$. RERs were detected in all 18 cancers from HNPCC patients but in only six of 65 non-HNPCC familial colorectal cancer kindreds $\left(9 \% ; \chi^{2}=52.2\right.$, $\mathbf{p}<0.0005)$. These findings suggest that most cancers in patients diagnosed at 45 years of age or less and familial aggregations of colorectal cancer which do not fulfil HNPCC diagnostic criteria do not have germline mutations in MSH2 and MLH1. Hence population screening for germline mutations in these genes is unlikely to be an efficient strategy for identifying people at high risk of developing colorectal cancer.

(f Med Genet 1996;33:981-985)

Key words: microsatellite instability; familial colorectal cancer.
Colorectal cancer is a leading cause of cancer related death and genetic factors are important determinants of colorectal cancer susceptibility. Segregation analysis suggests that approximately $5 \%$ of cases can be attributed to high penetrance single gene effects and a further $10-15 \%$ may result from polygenic effects. ${ }^{1-3}$ Germline mutations in the APC gene and in certain DNA mismatch repair (MMR) genes can both cause familial colorectal cancer. APC gene mutations produce classical or attenuated familial polyposis coli, but these disorders account for only about $1 \%$ of all colorectal cancers. ${ }^{45}$ Mutations in MMR genes, principally MSH2 and MLH1 but also PMS1 and PMS2, cause hereditary non-polyposis colorectal cancer syndrome (HNPCC). ${ }^{6-10}$ The precise incidence of HNPCC is uncertain and estimates of the population frequency vary from 1 in 200 to 1 in 2000 . These estimates reflect variability in the age at onset of colorectal cancer in HNPCC and the diagnostic difficulties posed by the absence of a distinctive clinical phenotype. The most widely used diagnostic criteria for HNPCC, ${ }^{11}$ the "Amsterdam criteria", require that there should be (1) three or more family members with histologically verified colorectal cancer, (2) with one member being a first degree relative of the other two; (3) that at least one case should have been diagnosed before the age of 50 years; and (4) that two or more generations are involved. Although it appears that most families satisfying these criteria will have germline $\mathrm{MSH} 2$ or MLH1 mutations, ${ }^{12-17}$ most cases of familial colorectal cancer seen in family cancer clinics only partially fulfil these criteria. ${ }^{18}$ In a population based series of 1100 consecutive colorectal cancer patients, $10 \%$ of cases had a first degree relative with colorectal cancer, but only $0.4 \%$ of all cases fulfilled the HNPCC diagnostic criteria (Evans et al, in preparation). It is not clear if the current HNPCC diagnostic criteria are overly restrictive and exclude large numbers of families or early onset cases who will have germline MMR gene mutations. Cancers from HNPCC patients with MMR gene mutations characteristically display DNA replication errors (RERs). ${ }^{19}$ We therefore examined cancers from a population based series of patients with early onset colorectal cancer (45 years or less) and in families which only partially satisfy the Amsterdam HNPCC criteria for evidence of RERs. Our results suggest that most cancers from the above groups of patients do not exhibit the RER phenotype, implying that they are unlikely to have germline mutations of the mismatch repair genes $\mathrm{MSH} 2$ and $\mathrm{MLH} 1$. 
Materials and methods

PATIENT SELECTION

Colorectal cancers from patients with early onset colorectal cancer and familial colorectal cancer were examined for RERs. Patients with early onset colorectal cancer ( $<45$ years) were identified from population based surveys in north west and eastern England. Appropriate pathological material was available for 33 randomly ascertained cases.

To investigate the genetic epidemiology of familial colorectal cancer the records of all patients with colorectal cancer attending the Family Cancer Clinics in East Anglia were reviewed and HNPCC was diagnosed according to the Amsterdam criteria. ${ }^{11}$ Pathological material for RER analysis was available for 18 subjects from $12 \mathrm{HNPCC}$ families and 76 subjects from 65 non-HNPCC familial colorectal cancer kindreds. Each of the 65 nonHNPCC families contained two or more relatives with colorectal cancer but only partially satisfied the HNPCC diagnostic criteria. In $72 \%(47 / 65)$ of these kindreds, the probands had first degree relatives with colorectal cancers and, within this group, there was at least one affected person diagnosed below 50 years in 16 kindreds; 7/65 kindreds had a first degree relative with a HNPCC related cancer (endometrial, ovarian, or urothelial).

PREPARATION OF PATHOLOGICAL MATERIAL

DNA was extracted from both frozen tumours and paraffin embedded formalin fixed samples. The former was performed using the Puregene Kit (Gentra Systems Inc, Flowgen Instruments Ltd, Sittingbourne, Kent). The latter involved microdissection to remove non-neoplastic tissue from $5 \mu \mathrm{m}$ unstained paraffin block sections of tumour, using an adjacent haematoxylin and eosin stained serial section as a guiding template. Extraction of DNA was then performed by deparaffinisation in xylene and ethanol, followed by digestion with Proteinase K (SigmaAldrich Company Ltd, Poole, Dorset) in extraction buffer at $55^{\circ} \mathrm{C}$ overnight, and subsequent inactivation of the enzyme at $95^{\circ} \mathrm{C}$. PCR was performed directly on an aliquot of this digest. DNA from blood leucocytes was extracted by standard methods.

MOLECULAR GENETIC ANALYSIS

To determine microsatellite instability, DNA from both normal and tumour tissue was genotyped with microsatellite markers D2S123, D3S1076, D5S404, LNSCA, D8S255, D10S197, D13S175, D17S795, or DXS43. ${ }^{20-24}$ These primers produced fragments up to 250 base pairs in length. Amplifications were performed with ${ }^{32} \mathrm{P}$-ATP as described previously. ${ }^{14}$ Each sample pair consisted of carcinoma and normal DNA. Conditions used for PCR varied for each primer pair and the PCR products were separated in $6 \%$ denaturing polyacrylamide gels and subjected to autoradiography.

Five loci were typed initially and unequivocal results were obtained in most cases, with
Table 1 Details of RER + and RER-tumours in patients with colorectal cancer aged 45 years or less

\begin{tabular}{lll}
\hline & $R E R+$ & $R E R-$ \\
\hline Age at diagnosis, mean (SD) & $38.0(3.6)$ & $39.7(4.6)$ \\
Multiple primaries & $1 / 7$ & $0 / 23$ \\
Site: proximal:distal to splenic & & \\
flexure & $5: 2$ & $4: 22$ \\
Size (cm) & $4.7(2.3)$ & $3.95(1.3)$ \\
Lymph node involvement & $2 / 6$ & $13 / 23$ \\
\hline
\end{tabular}

tumours being classified as RER positive (two or more of five markers showing microsatellite instability) or RER negative (none of five markers). In four of the familial cases, tumours were unstable at only one of five markers and were then tested with four additional markers with no further instability detected.

\section{Results}

HNPCC KINDREDS

All 18 cancers from 12 HNPCC families showed DNA-RERs at two or more of five loci tested. For 10 cancers from six families, previous studies had shown a germline MMR gene mutation ${ }^{25}$ and another five cancers were from four families linked to MSH2 or MLH1. ${ }^{14}$

EARLY ONSET COLORECTAL CANCER

Overall, microsatellite instability was detected in seven of $33(21 \%)$ colorectal cancers of patients aged 45 years or less at diagnosis.

Seven of the patients tested had developed colorectal cancer aged 35 years or less, and three of these had inflammatory bowel disease (two ulcerative colitis, one Crohn's disease); none of these three tumours displayed RERs. Of the remaining four patients, one showed an

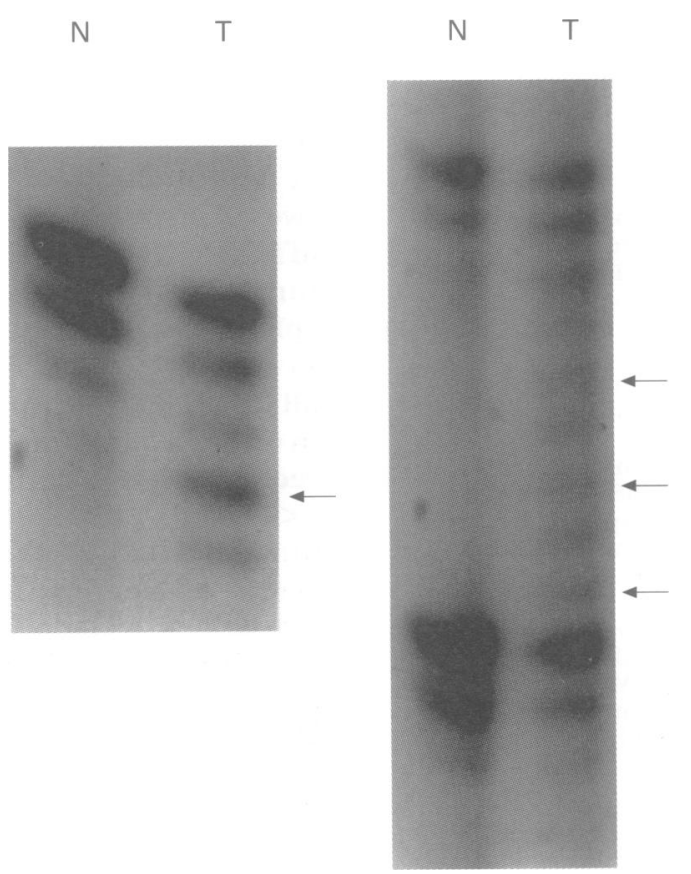

Figure 1 Microsatellite instability at the D2S123 locus in tumours from two familial colorectal cancer cases (No 70 on left and No 67 on right). Additional alleles indicated by arrows. $N=$ normal colonic epithelium, $T=$ colorectal cancer. 

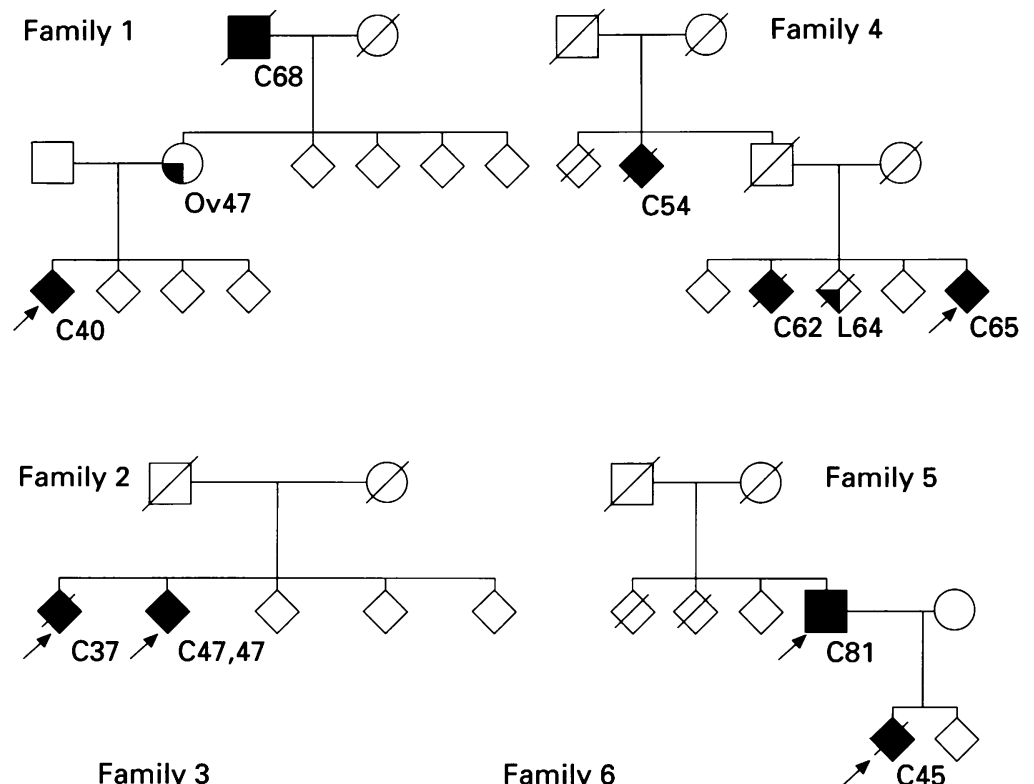

Family 3

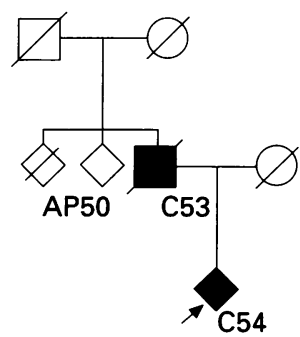

Family 6

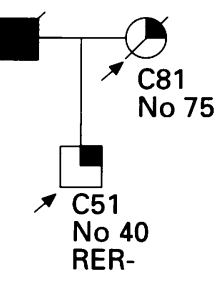

Figure 2 Partial pedigrees of the six families with patients with RER + tumours. Filled symbols = subjects affected by colorectal cancer, partially filled symbols $=$ other significant feature. $C 54=$ colorectal cancer age $54, O v=$ ovarian cancer, $A P=$ adenomatous colonic polyp, $L=$ liver cancer (?primary or secondary). Arrows indicate which patients for which $R E R$ status was determined and cancer numbers are indicated (for example, No 76). All cancers were RER + except for Nos 76 and 40 in families 5 and 6 respectively.

RER + phenotype; this was a 31 year old male with no family history of cancer.

Of the 26 people diagnosed between 36 and 45 years of age, six had RER + tumours, with only two cases being associated with a family history of HNPCC. Of the remaining four RER + cases, only one had a family history of cancer, two had no family history of cancer, and one was adopted with no available clinical details.

Clinical and histopathological characteristics of RER + and RER - cases were similar (table 1) except that most RER + cancers were proximal to the splenic flexure (5/7 v 4/26 RERtumours; $\left.\chi^{2}=6.14, \mathrm{p}<0.025\right)$.

\section{FAMILIAL COLORECTAL CANCER}

Cancers from only seven patients from six of the 65 non-HNPCC familial colorectal cancer kindreds were RER+ (fig $1 ; \chi^{2}=52.2$, $\mathrm{p}<0.0005$ compared to HNPCC). The frequency of RER + cancers did not differ between those kindreds in which all affected subjects were aged $>50$ years (3/37) and those containing a person affected $<50$ years of age (3/28). The mean age at diagnosis of RER + and RER - cancers was similar (53.8, SD 15.1, and 56.9, SD 13.2, respectively), but RER+ tumours were more frequently situated proximal to the splenic flexure (7/7 compared to
$17 / 63$ of RER - tumours for which information was available) and were larger than RERcancers $(5.8 \mathrm{~cm}, \mathrm{SD} 1.6$, in length $v 4.2, \mathrm{SD}$ $1.5 \mathrm{~cm}$, respectively).

The family histories of the six kindreds containing RER + tumours were reviewed in detail, and partial pedigrees (to preserve confidentiality) are shown in fig 2 . In families 1 and 2, the probands (Nos 7 and 66) had early onset cancer and the family history is suggestive of HNPCC even though they do not satisfy the strict criteria. For the other four families the RER + cancer was from a person aged $>50$ years at diagnosis and might have resulted from somatic MMR gene mutations only. This is likely to be the case in families 5 and 6 in which the RER+ phenotype was not consistent.

In addition to the six kindreds with RER + tumours, four cancers showed RERs at only one of the five loci initially tested. Two cancers were from patients with late onset tumours (61 and 77 years respectively) and two with early onset tumours (No 49 at 35 years and No 62 at 28 years). RERs were detected at only one of nine loci in the cancer from No 49 and the cancer from the proband's mother (diagnosed aged 51 years) was RER - The father of No 62 had colorectal cancer aged 72 years, but there was no other family history of colorectal cancer.

\section{Discussion}

We have investigated the frequency of microsatellite instability in the tumours from a population based series of young onset colorectal cancer patients and in familial colorectal cancer kindreds ascertained through a family cancer clinic. The incidence of clinically diagnosed cases of HNPCC in our young onset patients $(2 / 33)$ is similar to that reported by Hall et $a l^{18}$ in a comparable group (5/65), suggesting that our study group was representative. Defective DNA mismatch repair resulting in DNA RERs requires inactivation of both alleles of an MMR gene. These mutations might be germline and somatic in HNPCC cancers or somatic only in sporadic cancers. Thus, although the identification of an RER + cancer is not specific for a germline MMR gene mutation, the detection of RERs is likely to be a sensitive screening method for HNPCC cancers as microsatellite instability was identified in all the HNPCC tumours we tested. Hence the frequency of RER + tumours can provide a maximum incidence for the incidence of germline MMR gene mutations in the populations studied. Our results suggest that germline MSH2 and MLH1 gene mutations account for only a minority of early onset and non-HNPCC familial colorectal cancer.

Liu et $a l^{26}$ have also investigated the frequency of RER + cancers in early onset cases without a family history of HNPCC. They found that almost $60 \%$ of patients with colorectal cancer aged 35 years or less had RER + tumours. Familial cancers have (on average) an earlier age at onset than sporadic cases and intuitively we might expect that many patients with early onset RER + colorectal cancers 
would have germline MMR gene mutations, even in the absence of a family history of HNPCC. We found that among cases diagnosed from 36 to 45 years of age, six of 26 had RER + tumours but only two of these had a family history of HNPCC so that the incidence of RER + tumours in patients affected between 36 and 45 years of age without a family history of HNPCC was $17 \%(4 / 24)$ compared to $5 \%$ $(1 / 20)$ of a comparable group investigated by Liu et al. ${ }^{26}$ Combining the results of the present study and that of Liu et $a l^{26} 54 \%$ of nonHNPCC patients with colorectal cancer aged 35 years or less have RER + cancers, and $11 \%$ of cases affected between 36 and 45 years of age. Liu et $a^{26}$ identified a germline MMR gene mutation in five of 12 patients with RER + cancer aged $<35$ years. Current RNA based diagnostic methods can only detect mutations in $\sim 50 \%$ of HNPCC kindreds. ${ }^{25}$ In the absence of available RNA we have not been able to confirm that our early onset cases with RER+ tumours have MMR gene mutations, but the results of Liu et $a l^{26}$ suggest that this will be so. Patients with colorectal cancers with an age of onset at 35 years or less account for only $\sim 0.6 \%$ and those aged 36 to 45 years account for $\sim 2.3 \%$ of all cases of colorectal cancer. Thus, although the identification of patients with germline MMR gene mutations in the absence of a family history is important, with the exception of patients with a very early age at onset, most young colorectal cancer patients without a family history of HNPCC are unlikely to have germline MMR gene mutations.

The identification of HNPCC kindreds by finding RER + tumours in young onset patients confirms the usefulness of analysis of tumour microsatellite instability in the diagnosis of HNPCC. Our results suggest that, in our population, most patients with clinically diagnosed HNPCC will have germline MMR gene mutations (all HNPCC cancers were RER+) and that overdiagnosis of HNPCC is uncommon. Our results differ from those reported by Jass et $a l,{ }^{27}$ who (using a less strict definition for an RER + tumour) found that only 12 of 19 HNPCC kindreds from New Zealand were RER + . In their study, RER - HNPCC families were smaller than RER + kindreds, and the overdiagnosis of HNPCC using the Amsterdam criteria in New Zealand may reflect the high incidence of colorectal cancer in New Zealand and the presence of phenocopies within their families. Our results do not suggest that the application of the Amsterdam criteria results in widespread underdiagnosis of HNPCC in England, but formal clinical recognition of small HNPCC families would be enhanced by incorporating the presence of early onset HNPCC associated extracolonic cancers (for example, uterine, ovarian, and urothelial) into the diagnostic criteria. Similarly, the presence of proximal tumours is strongly associated with HNPCC. Testing cancers for RER status can help to resolve HNPCC diagnostic difficulties and to target people with early onset and familial colorectal cancer who should be screened for germline MMR gene mutations. Nevertheless, we found that most families with non-
HNPCC familial colorectal cancer do not have the RER + phenotype indicative of MMR gene mutations. Most HNPCC families have MSH2 or MLH1 mutations and mutations in these genes produce DNA replication errors which are most readily detected by simple dinucleotide repeat polymorphisms as used in this study. Mutations in other components of the mismatch repair system (for example, the GTBP gene) might produce DNA RERs which would be detected more readily by other types of repeat sequences (for example, mono- or trinucleotide repeats). ${ }^{2829}$ However, cancers with a low level of RERs were infrequent in our study and Jass $e t a l,{ }^{27}$ who used less strict criteria for the diagnosis of RER + tumours (microsatellite instability at one or more of six loci) also found that underdiagnosis of HNPCC was infrequent. This leads us to conclude that only a minority of non-HNPCC colorectal cancer susceptibility is accounted for by MMR gene mutations. Furthermore, the low frequency of large HNPCC kindreds with RER - tumours may suggest that many small familial clusters of colorectal cancer result from polygenic effects, rather than highly penetrant monogenic disorders. Only six out of 65 familial clusters in our study were RER +, suggesting a maximal HNPCC incidence of only $8 \%$ in such kindreds. This equates to a low overall frequency of HNPCC in sporadic colorectal cancer and implies that the Amsterdam criteria, at least in the UK, are appropriate for classification. The isolation of MSH2 and MLH1 has led to suggestions that widespread DNA testing for germline MMR gene mutations could be imminent, but our present findings suggest that MMR gene mutations are likely to be rare in the general population and that mutation analysis in non-HNPCC families should be preceded by an initial analysis for RERs in cancers and polyps.

We thank Addenbrooke's NHS Trust Endowment Fund, East Anglian Regional Health Authority, and the Cancer Research Campaign (CRC) for financial support, and Sian Wombwel for technical assistance. We are grateful to Dr Hamid, Mr E M Hoare, Mr R Kingston, Mr P Sykes, and Mrs Jane Koch for help in obtaining samples. CB performed this work towards an MChir degree of the University of Cambridge.

1 Houlston RS, Collins A, Slack J, Morton NE. Dominant genes for colorectal cancer are not rare. Ann Hum Genet 1992;56:99-103.

2 Scapoli C, Ponz de Leon M, Sassatelli R, et al. Genetic epidemiology of hereditary non-polyposis colorectal cancer syndromes in Modena, Italy: results of a complex cer syndromes in Modena, Italy: results of a complex
segregation analysis. Ann Hum Genet 1994;58:275-95.

3 Cannon-Albright LA, Skolnick MH, Bishop T, Lee RG, Burt RW. Common inheritance of susceptibility to colonic adenomatous polyps and associa

4 Spirio L, Olschwang S, Groden J, et al. Alleles of the APC gene: an attenuated form of familial polyposis. Cell 1993 75:951-7.

5 Nagase N, Nakamura Y. Mutations of the APC (adenomatous polyposis coli) gene. Hum Mutat 1993;2:425 34

6 Fishel R, Lescoe MK, Rao MRS, et al. The mutator gene homolog MSH2 and its association with hereditary nonpolyposis colorectal cancer. Cell 1993;75:1027-38.

7 Leach FS, Nicolaides NC, Papadopoulos N, et al. Mutation of a mutS homolog in hereditary nonpolyposis colorectal cancer. Cell 1993;75:1215-25.

8 Papadopoulos N, Nicolaides NC, Wei YF, et al. Mutation of a mutL homolog in hereditary colon cancer. Science 1994;263:1625-9.

9 Bronner CE, Baker SM, Morrison PT, et al. Mutation in the DNA mismatch repair gene homologue hMLH1 is the DNA mismatch repair gene homologue hMLH1 is Nature 1994;368:258-61. 
10 Nicolaides NC, Papadopoulos N, Liu B, et al. Mutations of two PMS homologues in hereditary non-polyposis colon cancer. Nature 1994;371:75-80.

11 Vasen HF, Mecklin JP, Khan PM, Lynch HT. The International Collaborative Group on Hereditary Non-Polyposis Colorectal Cancer (ICG-HNPCC). Dis Colon Rect 1991;34:424-5.

12 Nystrom-Lahti M, Parsons R, Sistonen P, et al. Mismatch repair genes on chromosomes $2 p$ and $3 p$ account for a major share of hereditary nonpolyposis colorectal cancer families evaluable by linkage. Am $\mathcal{F}$ Hum Genet 1994;55. 659-65.

13 Liu B, Parsons RE, Hamilton SR, et al. hMSH2 mutations in hereditary non-polyposis colorectal cancer kindreds. Cancer Res 1994;54:4590-4.

14 Froggatt NJ, Koch J, Davies R, et al. Genetic linkage analysis in hereditary nonpolyposis colon cancer syndrome. $7 \mathrm{Med}$ Genet 1995;32:352-7.

15 Wijnen J, Vasen H, Khan PM, et al. Seven new mutations in $\mathrm{hMSH} 2$, an HNPCC gene, identified by denaturing gradient-gel electrophoresis. Am f Hum Genet 1995;56: gradient-gel $1060-6$.

16 Buerstedde JM, Alday P, Torhurst J, Weber W, Muller H, Scott R. Detection of new mutations in six out of 10 Swiss Scott R. Detection of new mutations in six out of 10 Swiss
HNPCC families by genomic sequencing of the hMSH2 HNPCC families by genomic sequencing of the hMS
and hMLH1 genes. F Med Genet 1995;32:909-12.

17 Froggatt NJ, Joyce JA, Davies R, et al. A frequent hMSH2

18 Hall NR, Finan PJ, Ward B, Turner G, Bishop DT. Genetic susceptibility to colorectal cancer in patients under 45 years of age. Br $\mathcal{F}$ Surg 1994;81:1485-9.

19 Aaltonen LA, Peltomaki P, Mecklin JP, et al. Replication errors in benign and malignant tumors from hereditary nonpolyposis colorectal cancer patients. Cancer Res 1994; 54:1645-64.

20 Weissenbach J, Gyapay G, Dib C, et al. A second generation linkage map of the human genome. Nature 1992;359: 794-801.

21 Gyapay G, Monsette J, Vignal A, et al. The 1993-1994 Genethon human genetic linkage map. Nat Genet 1994; 7:246-339.

22 Jones $\mathrm{MH}$, Yamakawa K, Nakamura Y. Isolation and characterisation of 19 dinucleotide repeat polymorphisms on chromosome 3p. Hum Mol Genet 1992;1:131-3.

23 Spirio L, Nelson L, Ward K, Burt R, White R, Leppert M A CA-repeat polymorphism close to the adenomatous polyposis coli (APC) gene offers improved diagnostic testing for familial APC. Am $\mathcal{F}$ Hum Genet 1993;52:286-96 24 Alitalo T, Kruse TA, Ahrens P, Albertsen HM, Eriksson AW, de la Chapelle A. Genetic mapping of 12 marker loci in the Xp22.3-21.2 region. Hum Genet 1991;86:599-603.

25 Froggatt NJ, Brassett C, Koch DJ, et al. Mutation screening of MSH2 and MLH1 mRNA in hereditary non-polyposis colon cancer syndrome. 7 Med Genet 1996;33:726-30.

26 Liu B, Farrington SM, Petersen GM, et al. Genetic instability occurs in the majority of young patients with stability occurs in the majority of young
colorectal cancer. Nat Med 1995;1:348-52.

27 Jass JR, Cottier DS, Jeevaratnam P, et al. Diagnostic use of microsatellite instability in hereditary non-polyposis colorectal cancer. Lancet 1995;346:1200-1.

28 Drummond JT, Li GM, Longley MJ, Modrich P. Isolation of an hMSH2-p160 heterodimer that restores DNA mismatch repair to tumour cells. Science 1995;268:1909-12.

29 Palombo F, Gallinari P, Iaccarino I, et al. GTBP, a 160kilodalton protein essential for mismatch-binding activity in human cells. Science 1995;268:1912-17. 